\title{
Advanced interdisciplinary undergraduate program: light engineering
}

\section{Alexey Bakholdin, Vladislav Bougrov, Anna Voznesenskaya, Kseniia Ezhova}

Alexey Bakholdin, Vladislav Bougrov, Anna Voznesenskaya, Kseniia Ezhova, "Advanced interdisciplinary undergraduate program: light engineering," Proc. SPIE 9946, Optics Education and Outreach IV, 994612 (27 September 2016); doi: $10.1117 / 12.2237751$

Event: SPIE Optical Engineering + Applications, 2016, San Diego, California, United States 


\title{
Advanced interdisciplinary undergraduate program: Light Engineering
}

Alexey Bakholdin, Vladislav Bougrov, Anna Voznesenskaya, Kseniia Ezhova* ITMO University, 49 Kronverkskiy Prospect, Saint Petersburg, Russia, 197101

\begin{abstract}
The undergraduate educational program "Light Engineering" of an advanced level of studies is focused on development of scientific learning outcomes and training of professionals, whose activities are in the interdisciplinary fields of Optical engineering and Technical physics. The program gives practical experience in transmission, reception, storage, processing and displaying information using opto-electronic devices, automation of optical systems design, computer image modeling, automated quality control and characterization of optical devices. The program is implemented in accordance with Educational standards of the ITMO University. The specific features of the Program is practice- and problem-based learning implemented by engaging students to perform research and projects, internships at the enterprises and in leading Russian and international research educational centers. The modular structure of the Program and a significant proportion of variable disciplines provide the concept of individual learning for each student. Learning outcomes of the program's graduates include theoretical knowledge and skills in natural science and core professional disciplines, deep knowledge of modern computer technologies, research expertise, design skills, optical and optoelectronic systems and devices.
\end{abstract}

Keywords: images educational standards, undergraduate educational program

\section{INTRODUCTION}

The realized at the Faculty of Laser and Light Engineering, ITMO University advanced undergraduate program "Light Engineering" is focused on the development of scientific learning outcomes and training of competitive specialists, whose activities are directed on conducting of research in the interdisciplinary fields of "Optical Engineering" and "Technical Physics" in investigation and development of optical and optoelectronic systems and devices for different purposes.

The educational program generates the experience of practical and research activities in transmission, reception, storage, processing and display of information by optical-electronic devices, optical systems design automation, computer simulation imaging, study of automated methods for quality control of optical systems and devices

Development of the basic concept of the educational program and its implementation is carried out in cooperation between the department of Applied and computer optics and the department of Light technologies and optoelectronics, ITMO University.

\section{SHORT DESCRIPTION OF THE EDUCATIONAL PROGRAM}

The advanced undergraduate educational program "Light Engineering" is realized according to the Federal educational standards for higher education of Russian Federation as well as ITMO University educational standards jointly by departments of Applied and computer optics and the Light technologies and optoelectronics, in partnership with European universities leading in Optical Engineering - Warsaw University of Technology, University of Eastern Finland, Aalto University [1]. The advanced level of education is provided through research projects, which are implemented by students and are started from the first year of studies. The program is focused as well on advanced study of the English, communication and academic writing. A number of professional courses of the educational program is realized on English; professors from partner universities are involved to teaching [1].

*ezhovakv@aco.ifmo.ru; phone 7812 595-4165; ifmo.ru

Optics Education and Outreach IV, edited by G. Groot Gregory, Proc. of SPIE Vol. 9946, 994612

(C) 2016 SPIE · CCC code: $0277-786 X / 16 / \$ 18 \cdot$ doi: $10.1117 / 12.2237751$ 
The program integrates the best educational practices, academic staff and laboratory equipment of the leading departments of the University ITMO in the field of optical engineering and technical physics. The academic staff consists of highly qualified professors and industry experts The program is supported by necessary laboratory facilities, information resources and specialized software.

The feature of the Program concludes in application of the practice-oriented and problem-oriented approach through attracting students to implement research and engineering projects, practical training and scientific training at the specialized enterprises [2] and leading Russian and international scientific and educational centers, and a network of partner universities, such as: University of California, Aalto Unveristy, University of Tartu, Katholieke Universiteit Leuven, Tallinn University of Technology, Institut d'Optique, Warsaw University of Technology, Bar Ilan University [1].

The modular structure of the program and a large proportion of elective courses provide the concept of individualized study for every student.

Graduates of the program are focused on research and design activity and continuation of education in a scientific master's degree [1].

The area of professional activity of bachelors - graduates of the educational program "Light Engineering" includes a set of tools and methods of the identification, investigation and modeling of new physical phenomena and laws, with the development on their basis the development and introduction of new technologies, equipment, devices and materials various purposes in high-tech areas of applied and engineering physics.

The main features of the implementation of the educational program are the following:

- problem- and practice-oriented education starting from the first year;

- increased contact time and extended interaction with faculty members;

- extensive use of computer simulation means, computer-aided design and CALS-technologies;

- depth study of English;

- networked education - attracting the resources of universities and partner organizations (internship of students, visiting professors, distance learning technologies);

- students participate in current research works of the departments;

- students participate in conferences, optical Olympiads, grants competitions;

- internship of students in the leading scientific and educational centers in Russia and abroad;

- modules of academic mobility.

\section{REQUIREMENTS FOR THE GRADUATES OF THE EDUCATIONAL PROGRAM}

A graduate who has completed the advanced program "Light engineering" must be able to solve the following professional tasks:

- study the scientific and technical information, the Russian and foreign experience in the chosen field of technical physics;

- analysis of the given task for research in the field of technical physics on the basis of selection and study of literature and patent sources;

- development of mathematical models to analyze the properties of the objects of research and choice of tools and software to implement them;

- measurements and research of physical and technical objects with a choice of means of measurement and processing of the results;

- compiling descriptions of the research and development projects, preparation of data for reporting, reviews and other technical documentation;

- participation in the preparation of reports, articles, essays on the basis of modern means of editing and printing;

- implementation of adjustment, tuning and experimental verification of complex physical and technical devices and systems in the laboratory and in the manufacturing environment.

In the educational process the following learning outcomes are formed: 
- the ability to apply effective methods to study physical and technical objects and materials; to carry out standard and certification tests of processes and products using modern analytical tools of Technical Physics;

- the ability to study the scientific and technical information, national and international experience on the subject of professional activity;

- the ability to make a plan of the specified research, to develop an adequate model of the investigated object and define the area of its applicability;

- the ability to perform mathematical modeling of processes and objects of the optical engineering and their investigation on the basis of standard CAD tools and self-developed software products;

- the ability to carry out experimental measurements of optical, electrical and photometric values and research of different objects with a given procedure;

- the ability to develop presentations, scientific and technical reports on the achieved results, to issue the results of research in the form of papers and reports on scientific conferences;

- the ability to setup, tuning, adjust and experimental verification of optical, opto-electronic devices and systems.

\section{STRUCTURE OF THE EDUCATIONAL PROGRAM}

The advanced educational program "Light engineering" is defined by the unity of the core part and the learning outcomes and consists of the following units:

- Unit 1 "Courses (modules)", which includes courses (modules), related to the core part of the program and courses (modules) related to its elective part.

- Unit 2 "Internship", which is fully related to the elective part of the program.

- Unit 3 "State final examination", which is fully related to the core part of the program.

The educational program core, formed on the basis of educational standards and is a combination of the base portion that is bound to develop in the framework of the bachelor's program, and variable component is presented in Table 1.

Table 1.

\begin{tabular}{|l|c|}
\hline \multicolumn{1}{|c|}{ Program educational elements: units, modules, courses } & workload \\
\hline \multicolumn{1}{|c|}{ Unit 1Courses (modules)" } & ECTS \\
\hline Core part & $\mathbf{1 2 4}$ \\
\hline Humanities module & $\mathbf{9}$ \\
\hline History & 3 \\
\hline Philosophy & 3 \\
\hline$*$ & 3 \\
\hline Socio-economic module & $\mathbf{9}$ \\
\hline Economy & 3 \\
\hline law & 3 \\
\hline$*$ & 3 \\
\hline Design and entrepreneurial module & $\mathbf{6}$ \\
\hline Introduction to the design activity & 2 \\
\hline Project activity & 4 \\
\hline Foreign language & $\mathbf{2 0}$ \\
\hline English & 20 \\
\hline Natural Sciences, Mathematics and Information Module & $\mathbf{6 0}$ \\
\hline Mathematics & 15 \\
\hline Physics & 12 \\
\hline Chemistry & 3 \\
\hline Ecology & 3 \\
\hline In-depth scientific, informational and mathematical training & $\mathbf{2 7})$ \\
\hline Computing \& information technology & 3 \\
\hline Mathematical physics & 3 \\
\hline Special parts of informatics & 3 \\
\hline Computational mathematics & 3 \\
\hline
\end{tabular}




\begin{tabular}{|l|c|}
\hline Computer engineering graphics & 3 \\
\hline Basics optics & 3 \\
\hline Physical optics & 3 \\
\hline Physical material science & 3 \\
\hline Electrodynamics and crystal optics & 3 \\
\hline General professional module & $\mathbf{1 8}$ \\
\hline Health and safety & 3 \\
\hline Metrology, standardization, certification & 3 \\
\hline Electrical engineering, electronics and microprocessor technology & 3 \\
\hline Laser technique and laser technology & 3 \\
\hline Optoelectronic devices and systems & 3 \\
\hline Optoelectronics and light engineering & 3 \\
\hline Physical training & $\mathbf{2}$ \\
\hline Physical training & 2 \\
\hline Elective part & $\mathbf{8 9}$ \\
\hline Discipline profile, including interdisciplinary project & $\mathbf{7 1}$ \\
\hline Elective courses (20\% from elective part) & $\mathbf{1 8}$ \\
\hline Unit 2 “Internship" & $\mathbf{2 1}$ \\
\hline Educational & 3 \\
\hline Manufacturing & 6 \\
\hline Pregraduation & 12 \\
\hline State final examination & $\mathbf{6}$ \\
\hline TOTAL & 6 \\
\hline
\end{tabular}

The workload of the educational program is presented in Table 2 .

Table 2 .

\begin{tabular}{|l|c|}
\hline The total workload of the educational program (ECTS) & 240 \\
\hline Academic hours of the theoretical training: & 8968 \\
\hline Contact time, hours & 3754 \\
\hline Classroom hours & 3211 \\
\hline Lectures & 968 \\
\hline (a percentage of the classroom hours) & $30 \%$ \\
\hline The volume of elective courses: & 3456 \\
\hline
\end{tabular}

Courses of the core part of the educational program are: Physical Culture, Higher mathematics, Linear algebra, Physics, Information technology, Electronics and microprocessor technology, History, Computer engineering graphics, Chemistry, English, Additional chapters of mathematics - Computational Mathematics, Additional chapters of mathematics - basics of Fourier analysis, Basic programming, Legal basics of professional work, Ecology, Basics of electrical engineering, Fundamentals of innovation activities, Health and safety, Metrology, standardization, certification, Basics on laser technology, Sources and receivers of optical radiation, Philosophy of science and technology, Introduction to the profession. The presented courses are needed for the development the general engineering, humanities, social and natural science learning outcomes.

The elective part is purposed to develop individual learning paths through selection of courses (modules) and internship topics from a list proposed by the scientific supervisor of the educational program.

Courses of the elective part of the educational program are: Theoretical and applied mechanics, Basics of computer design, Basics Optics (geometrical optics), Basics Optics (physical optics), Basics of materials science, Applied geometric optics, Applied optics, Optical measurement, Basics of light engineering, Basics design of optical systems, Physical foundations of quantum electronics, Physical modeling, Mathematical methods of physics, Application development, Quantum mechanics, PLM-technologies in instrument making, Surface physics and nanotechnology, Basics of laser technology, Laser-based optics, Experimental research methods, Basics design of optoelectronic devices and systems, Fluid sensors, Optical information instruments, Methods optical-physical and laser measurements, 
Information support of the development of optical devices, Optical technologies and materials, Methodology of designing technical systems, Methodology of designing optical devices, Computational methods in optics, Numerical methods in technical physics, Solid state optoelectronics, Basics of holography and holographic optics, Applications of information technologies in physical experiments, Modeling of optical systems, Model design of optical devices, Methods for calculating optical systems, Methods of controlling the parameters of the laser, Assembly, adjustment and control of optical devices, Basics of business planning, Computer aided designing optical devices, Optical information, Ergonomics of visual activity, Sensory basics, Spectral devices, Thermodynamics and statistical mechanics, Basics of thermal physics, Special optical elements, Communication basics.

The following courses of the elective part are studied in English: Fiber optics, Software for design of optical systems, Electronics and optoelectronics materials, Medical optical devices, Solid state physics.

\section{FLAGMAN COURSES OF THE EDUCATIONAL PROGRAM}

The following courses are flagman for the presented advance educational program:

- LEDs optoelectronics. The course gives exhaustive information about light-emitting diodes and solid-state light sources, based on them. It is told about the main types of LEDs, LED assemblies, made by "chip-on-board" technology, areas of application, achieved characteristics and a market forecast of solid-state light sources in the coming years.

- Basics of laser technology. The course forms the understanding of the physics of lasers and laser technology, its elemental base, characteristics and advantages of the laser radiation and the resulting opportunities for application of these lasers. At the laboratory work students will be able to investigate the main characteristics of various types of lasers.

- Optical informatics. The course forms the understanding of photonics, modern sources and receivers of optical radiation, basics of fiber optics, optical systems for recording and storage of information, practices and technology transfer, receiving, processing, storing and displaying information based on photons.

- Modeling of optical systems. The course forms the understanding about the features of computer modeling of optical phenomena using object-oriented technology, the principle of selection of efficient numerical methods for solving optical tasks; develops practical skills of independent development of software applications for modeling of optical phenomena at the language $\mathrm{C}++$, creating a modern user interface for optical applications programs.

- Basics of holography and holographic optics. The course forms the understanding of holography principles, types of holograms and a main registration schemes, the methods of analysis of the properties of holograms; creates the ability to calculate the diffraction efficiency of the relief-phase holograms, develops skills of experimental work, study holograms properties and restore them using the fields of the environment parameters to evaluate and justify the prospect of applying the elements of holographic optics into the optical marking, interference microscopes, optical memory systems, telecommunications and etc.

- Medical optical devices. The course forms the understanding of the variety of medical optical instruments, the basic concepts of physiological and ophthalmic optics, optometry, endoscopic equipment and operating microscopes; introduces the functional schemes and principles of construction of medical optical instruments; forms of modeling skills, design and operation of the main types of medical optical instruments, taking into account the specific features and safety and environmental standards.

\section{EXAMPLES OF BACHELOR PROJECTS}

As already discussed, the main direction of activity of graduates - research, however, the practice-oriented educational approach allows students to be attracted to solve practical problems within the framework of research and development work being conducted in frames of current projects of academic departments.

The following topics are examples of bachelor projects:

- Development of the automated safety system of a large sports center.

- Optical properties of water solutions of urea and application of refractometer methods to monitor their concentrations in the production environment.

- Development of an automated instrument for measuring LED luminous intensity curve. 
- Development of the blaster optical system.

- Development of the transmission of the optical-electronic complex to control the movement of cars in the back plane.

- Design of the optical system for the mobile phone camera.

- Design of the optical system for the gradient rigid endoscope.

\section{CONCLUSION}

The learning outcomes of the Program's graduates include theoretical knowledge and skills in natural sciences and general professional courses, in-depth knowledge of modern computer technologies, research experience, design skills of optical and opto-electronic systems and devices.

Graduates of the program work in leading Russian and foreign industrial companies, admit to the ITMO University master's programs with preferential terms.

After finishing education on the considered educational program all this allows to obtain young professional researchers to be involved in the research projects of the academic departments of the ITMO University.

\section{REFERENCES}

[1] Alexey Bakholdin, Malgorzata Kujawinska, Irina Livshits, Adam Styk, Anna Voznesenskaya, Kseniia Ezhova, Elena Ermolayeva, Tatiana Ivanova, Galina Romanova, Nadezhda Tolstoba, "Double degree master program "Optical design"," Proceedings of SPIE 9793, 979307 (2015).

[2] Alexey Bakholdin, Kseniia Ezhova, Anna Voznesenskaya, Tatiana Ivanova, Galina Romanova, Nadezhda Tolstoba, "Collaboration between applied and computer optics department of ITMO University with industry's leading manufacturers", Proceedings of SPIE 9793, 97932F (2015). 